\title{
Clinopodium vulgare L. subsp. vulgare Ekstresinin Antioksidan, Antimikrobial, Tirozinaz İnhibitor Aktiviteleri ve RP-HPLC ile Fenolik Bileşiklerinin Araştırılması
}

\author{
Investigation of Phenolic Compounds by RP-HPLC and Antioxidant, Antimicrobial, \\ Tyrosinase Inhibitor Activities of Clinopodium vulgare L. subsp. vulgare Extract
}

\author{
Sıla Özlem ŞENER ${ }^{1, a}$, Nuriye KORKMAZ ${ }^{2, b}$, Şeyda AKKAYA ${ }^{2, \mathrm{c}}$, Merve BADEM ${ }^{2, \mathrm{~d}}$, Rezzan \\ ALIYAZICIOĞLU* ${ }^{* 2, \mathrm{e}}$, Ufuk ÖZGEN ${ }^{1, \mathrm{f}}$, Şengül ALPAY KARAOĞLU ${ }^{3, \mathrm{~g}}$ \\ ${ }^{1}$ Karadeniz Teknik Üniversitesi, Eczacılık Fakültesi, Farmakognozi A.B.D., 61080, Trabzon \\ ${ }^{2}$ Karadeniz Teknik Üniversitesi, Eczacıllk Fakültesi, Biyokimya A.B.D., 61080 Trabzon \\ ${ }^{3}$ Recep Tayyip Erdoğan Üniversitesi, Fen Fakültesi, Biyoloji Bölümü, 53100 Rize
}

\author{
• Geliş tarihi / Received: 18.04.2017・Düzeltilerek geliş tarihi / Received in revised form: 01.02.2018 • Kabul tarihi / Accepted: 16.02 .2018
}

\begin{abstract}
$\ddot{O} \mathbf{z}$
Clinopodium vulgare L. subsp. vulgare, Clinopodium cinsine ve Lamiaceae familyasına mensup çok yıllık aromatik otsu bir bitkidir. Bu cins bitkiler sıklıkla geleneksel tedavide kullanılmaktadır. Farklı Clinopodium türlerinin farklı ekstrelerinin antioksidan, antimikrobiyal, tirozinaz inhibitör etkilerini ve HPLC ile fenolik bileșenlerinin analizini konu alan çalışmalar olmasına rağmen, Clinopodium vulgare L. subsp. vulgare ekstresinin bu özelliklerinin tümünü içeren herhangi bir çalışma bulunmamaktadır. Bu çalışmanın amacı C. vulgare subsp. vulgare metanol ekstresinin antioksidan, antimikrobiyal, tirozinaz inhibitör aktivitelerini ve HPLC analizi ile fenolik madde içeriğini belirlemektir. Ekstrenin fenolik bileşenleri ters faz yüksek performanslı sıvı kromatografisi (RP-HPLC) ile belirlendi. Antioksidan, tirozinaz inhibitör aktivite spektrofotometrik yöntemlerle ve antimikrobiyal aktivite disk difüzyon metodu ile incelendi. Ekstrenin toplam fenolik madde miktarı $27.9 \pm 0.4 \mathrm{mg}$ gallik asit eşdeğeri/g numune, 2,2-difenil-1-pikrilhidrazil (DPPH) radikal süpürme kapasitesi $\mathrm{IC}_{50}$ değeri $0.114 \pm 0.0004 \mathrm{mg} / \mathrm{mL}$ ve ferrik indirgeyici antioksidan güç (FRAP) değeri $1556 \pm 3 \mu \mathrm{M}$ troloks eşdeğeri/g numune olarak hesaplandı. Tirozinaz inhibisyon çalışma sonucuna göre ekstrenin $\mathrm{IC}_{50}$ değeri kojik asit standardından yüksek bulundu. HPLC ile analiz sonucunda protokatekuik asit, klorojenik asit, vanilin, sinapik asit ve benzoik asit tespit edildi. Ekstre, asid-hızl bakteri (M. smegmatis), bazı gram pozitif (S. aureus ve B. cereus) ve bazı gram negatif (Y. pseudotuberculosis) bakterilere karşı 1lımlı antibakteriyal aktivite gösterdi. Ancak C. albicans and S. cerevisiae türlerine karşı hiçbir antifungal aktivite göstermedi. Bu çalışmanın sonuçlarına göre, $\mathrm{C}$. vulgare subsp. vulgare yeni farmasotiklerin geliştirilmesinde potansiyel bir kaynak olarak düşünülebilir.
\end{abstract}

Anahtar kelimeler: Antioksidanlar, Antimikrobiyal, HPLC, Tirozinaz İnhibitör Aktivite

\begin{abstract}
Clinopodium vulgare L. subsp. vulgare is a perennial aromatic herbaceous plant belonging to Clinopodium genus and Lamiaceae family. This genus plants are often used in traditional therapy. There are no studies involving the whole of these properties of the Clinopodium vulgare L. subsp. vulgare extract, although there are studies about antioxidant, antimicrobial, tyrosinase inhibitor effects and analysis of phenolic compounds by HPLC of different extracts of different Clinopodium genus. The purpose of this study was to determine the phenolic composition by HPLC, and antioxidant, antimicrobial, and tyrosinase inhibitor activity of methanolic extract of $C$. vulgare subsp. vulgare. The phenolic compounds were determined by reverse phase high performance liquid chromatography (RP-HPLC). The antioxidant, tyrosinase inhibitor, and antimicrobial activities of the extract were examined by spectrophotometric methods, and disc diffusion method, respectively. The total phenolic content (TPC), 2,2-diphenyl-1-picrylhydrazyl radical scavenging activity (DPPH), and ferric reducing antioxidant power (FRAP) values of the extract were found 27.9 $\pm 0.4 \mathrm{mg}$ gallic acid equivalents per g sample, $0.114 \pm 0.0004 \mathrm{mg} / \mathrm{mL}$, and $1556 \pm 3 \mu \mathrm{M}$ trolox equivalents per g sample, respectively. $I C_{50}$ value of the extract according to the tyrosinase inhibitition study results was found higher than kojic acid standard. The protocatechuic acid, chlorogenic acid, vanillin, sinapic acid, benzoic acid were detected by HPLC analysis. The extract exhibited while moderate antibacterial activity against an acid-fast bacterium (M. smegmatis), some gram pozitive (S. aureus and B. cereus) and gram negative (Y. pseudotuberculosis) bacteria. But, antifungal activity was not showed against $C$. albicans and S. cerevisiae species. According to the results of this study, $C$. vulgare subsp. vulgare can be considered as a potential source for developing new pharmaceuticals.
\end{abstract}

Keywords: Antioxidants, Antimicrobial, HPLC, Tyrosinase inhibition

\footnotetext{
*e Rezzan ALIYAZICIOĞLU; rezzanaoglu@mynet.com; Tel: (0462) 37788 19; orcid.org/0000-0003-0143-8795

a orcid.org/0000-0001-7679-7165 borcid.org/0000-0003-3370-4787 $\quad{ }^{c}$ orcid.org/0000-0001-7261-7067

${ }^{\mathrm{d}}$ orcid.org/0000-0002-1265-5616 $\quad{ }^{\mathrm{f}}$ orcid.org/0000-0001-9839-6717 $\quad{ }^{\mathrm{g}}$ orcid.org/0000-0003-1047-8350
} 


\section{Giriş}

Tıbbi bitkiler halk ilacı olarak ilk çağlardan günümüze kadar yaygın olarak kullanılmaktadır. (Tosun vd., 2016). Bitkilerin birkaç etkiye birden sahip olması, uzun yıllardır kullanımı sonucunda yan etkilerinin bilinmesi, sentetik ilaçlara göre daha az yan etkiye sahip olması, bitkiye ulaşımın kolay olmasi ve tedavide kullanım formunun kolay hazırlanması gibi nedenlerden dolayı bitkiye ilgi her zaman yoğun olmaktadır (Birinci, 2008). Bitkilerden modern ilaç formları kullanılarak preparatlar hazırlanmakta ve bu preparatlara günümüzde farklı ülkelerde bitkiseller, bitkisel ilaçlar, fitofarmasötikler, fitoterapötikler ve geleneksel ilaçlar gibi farklı isimler verilmektedir. (Eruygur, 2014). Doğal florada bulunan bitkiler halk arasında ilaç, boya, baharat ve gida olarak da kullanımı uzun yıllardan beri süren bir kültür zenginliğimiz olmuştur (Çelikol, 2015).

Clinopodium vulgare cinsi Clinopodium vulgare L. subsp. vulgare ve Clinopodium vulgare subsp. arundanum olmak üzere iki alt türe ayrılmıştır (Kokdil, 1998). Clinopodium vulgare Lamiaceae familyasına ait çok yıllık aromatik otsu bir bitkidir. Kuzey yarım kürenin 1lıman bölgelerinde yaklaşık 2000-2500 m yükseklikte doğal olarak yetişmektedir. Yapılan bazı çalışmalarda bitkinin etanol ve propilen glikol ekstresinin antitümoral (Dzhambazov vd., 2002) ve antibakteriyel etkisinin (Opalchenova ve Obreshkova, 1999) olduğu belirtilmiştir. Clinopodium cinsine ait bazı türlerle ilgili yapılan çalışmalarda Clinopodium bolivianum bitkisinin anti-enflamatuvar etkisinin (Soumitra vd., 2017), Clinopodium macrostemum var. laevigatum bitkisinin DPPH radikalini süpürücü etkisinin (Turner, 2008; Villa-Ruano vd., 2013) olduğu, C. macrostemum var. macrostemum ise antioksidan, hepatoprotektif ve nöroprotektif etkili olduğu bulunmuştur (Perez, 2013).

Sağlıklı ve zinde bir yaşam sürdürebilmenin arka planında hem hücresel ve hem de organizmanın oksidan-antioksidan dengesi öne çıkmaktadır. Serbest radikal oluşumundaki artışa veya antioksidan sistemdeki yetersizliğe bağlı olarak organizmada oksidatif stres gelişmektedir. Serbest radikaller yiyeceklerde lipit peroksidasyonuna neden olmakta, bu da yiyeceklerin bozulmasina yol açmaktadır. Reaktif oksijen (ROS) ve reaktif azot türleri DNA hasarına da neden olabilmekte ve mutasyon meydana gelebilmektedir. Buna ek olarak reaktif oksijen ve reaktif azot türleri sitma, kalp hastalıkları, ateroskleroz, diyabet ve kanser gibi birçok hastalığa yol açmaktadırlar. Antioksidanlar, hücrelere zarar veren bu prooksidanları (reaktif oksijen ve azot türleri, serbest radikaller) etkin bir şekilde indirgeyerek az zararlı veya zararlı olmayan ürünlere dönüştürürler. $\mathrm{Bu}$ tehlikeli bileşiklerin varlığ sağlıklı bir yaşam için antioksidanları gerekli kılmaktadır (Cao vd., 1999). Bu nedenle doğal kaynaklardan, sentetik antioksidanların yerini tutabilecek yeni antioksidanların bulunması için yapılan çalışmalar giderek önem kazanmaktadır ve bu alanda yapılan araştırmalar artmaktadır.

Bitkilerin antimikrobiyal bileşikleri genellikle esansiyal yă̆ kısmında bulunmaktadır. $\mathrm{Bu}$ bileşikler bitkinin karekteristik aromasından sorumludurlar ve genellikle bitkilerden su buharı distilasyonuyla elde edilirler. Antimikrobiyal aktivite; bitkinin türüne, kompozisyonuna ve konsantrasyonuna, hedef mikroorganizmanın türüne ve yüküne, gıdanın kompozisyonuna, işleme ve depolama koşullarına bağlıdır. Proteinler, lipitler, tuzlar, $\mathrm{pH}$ ve sıcaklık fenolik maddelerin antimikrobiyal aktivitelerini etkileyen faktörlerdir (Sağdıç, 2003). Bitkinin antimikrobiyal etkinliğini belirlemek için çeşitli mikroorganizmalar kullanılarak inhibisyon analizleri yapılmıştır.

Tirozinaz, melanin biyosentezinin özellikle ilk basamağında L-tirozinin L-dopakinon ve Ldopakrom'a dönüşümünden sorumlu bir enzimdir. Tirozinaz memelilerde, omurgasızlarda, bitkilerde, mikroorganizmalarda bulunur ve bu yapılarda birçok biyolojik fonksiyona sahiptir (Solver-Rivas vd., 1999). Polifenoller enzim inhibitörleri arasında en yaygın olanlarıdır. Özellikle flavanoidler (stilbenler, kalkonlar, izoflavonoidler, izoflavonlar), uzun zincirli lipitler, steroidler bilinen inhibitörlerdir. Kojik asit tirozinazın en çok çalışılmış inhibitörüdür, aynı zamanda kozmetik alanında cilt beyazlatıcı ve gıda endüstrisinde enzimatik kararmayı önleyici gida katkısı olarak kullanılmaktadır (Chen vd., 1991). Birçok bitkinin yaprak, tohum çiçek ve kabuklarında yaygın olarak bulundukları için tirozinaz enzim aktivitesinin incelenmesi oldukça önemlidir.

$\mathrm{Bu}$ çalışmada ülkemizde ve dünyada halk ilacı olarak kullanılan $C$. vulgare $\mathrm{L}$. subsp. vulgare metanol ekstresinin çeşitli metodlarla antioksidan, antimikrobiyal, tirozinaz inhibitör aktivitelerinin ve fenolik bileşenlerin belirlenmesi ve yeni farmasotiklerin geliştirilmesinde potansiyel bir kaynak olarak kullanılabileceğinin gösterilmesi amaçlanmıştır. 


\section{Materyal ve Metot}

\subsection{Materyal}

\subsubsection{Bitkisel Materyalin Temini}

C. vulgare L. subsp. vulgare 2014 y1lının Mayıs ayında Sinop ilinden topland. Bitkinin botanik tanımlanması Karadeniz Teknik Üniversitesi Eczacılık Fakültesi'nde Prof. Dr. Ufuk Özgen tarafindan yapıldı. Ankara Üniversitesi Eczacılık Fakültesi'nde AEF 26697 herbaryum numarası ile saklandi.

\subsubsection{Kullanılan Kimyasal Maddeler}

Asetik asit, hidrojen klorür Merck (Darmstadt, Germany) firmasindan; folin reaktifi, metanol, 2,4,6-tri(2-piridil)-s-triazin (TPTZ), demir (III) klorür, sodyum asetat, troloks, 2,2-difenil-2pikrilhidrazil hidrat (DPPH), bütillenmiş hidroksi toluen (BHT), gallik asit, protokatekuik asit, protokatekul aldehid, p-hidroksi benzoik asit, klorogenik asit, vanilik asit, kafeik asit, vanilin, şiring aldehid, p-kumarik asit, ferulik asit, tirozinaz, L-dopa, kojik asit ve DPPH (2,2-difenil1-pikrilhidrazil) Sigma-Aldrich firmasından temin edildi (St. Louis, MO, USA).

\subsubsection{Kullanulan Laboratuvar Cihazlart}

Çalışmamızda HPLC (Agilent 1100, DAD 1200 Agilent Technologies, Waldbronn, Germany) cihazı, UV-VIS spektrofotometre (Spectro UVVIS Double PC-8 auto cell, Labomed), rotary evaporator sistemi (IKA ${ }^{\circledR}, \quad$ Werke, USA), çalkalayıcı (Heidolph Promax 2020), pH metre (Hanna pH 213, Romania), magnetik karıştırıcı (Heidolph MR 3001, Germany), su banyosu (Nüve, ST 402) kullanıldı.

\subsection{Metot}

\subsubsection{Ekstraksiyon}

Bitki numunesi toplanarak gölgede kurutuldu ve kurutulan kısımlar değirmen yardımıyla toz haline getirildi. Toz haline getirilen bitki numunesinin konsantrasyonu $10 \mathrm{mg} / \mathrm{mL}$ olacak şekilde metanol ile ekstrakte edildi. Ekstraksiyon işlemi 24 saat boyunca $30{ }^{\circ} \mathrm{C}$ 'de 1 sitıcılı karıştırıcıda yapıldı. Biyolojik aktivite tayinlerinde kullanılmak üzere bitki ekstresi $0-4{ }^{\circ} \mathrm{C}$ sakland.

\subsubsection{Toplam Fenolik Madde Miktarı Tayini}

Metanolik bitki ekstresinin toplam fenolik madde tayini Slinkard ve Singleton metoduna göre spektrofotometrik olarak belirlendi (Slinkard ve
Singleton, 1977). İlk olarak, deney tüplerine bitki ekstresinden $(10 \mathrm{mg} / \mathrm{mL}) 50 \mu \mathrm{L}$ ve standart olarak gallik asitten $(31.25,62.5,125,250,500,1000$ $\mu \mathrm{g} / \mathrm{mL}$ ) 50 'şer $\mu \mathrm{L}$ pipetlendi. Ardından her bir tüpe $2.5 \mathrm{~mL}$ saf su ve $250 \mu \mathrm{L}$ Folin-Ciocalteu reaktifi (1:10 saf su ile seyreltilmiş) eklendi. Tüm tüpler vortekslendikten sonra, oda sıcaklığında 3 dakika inkübe edildi. İnkübasyon sonrası tüm tüplere $750 \mu \mathrm{L} \%$ 7.5'lik $\mathrm{Na}_{2} \mathrm{CO}_{3}$ eklendi ve vortekslendi. Karışımlar oda sıcaklığında 2 saat bekletildi ve $765 \mathrm{~nm}$ 'de absorbans değerleri ölçüldü. Toplam fenolik madde miktarı gram numune başına mg gallik asit eşdeğeri olarak verildi.

\subsubsection{Antioksidan Aktivite Çalışmaları}

\subsubsection{2,2-difenil-1-pikrilhidrazil Radikal Süpürme Kapasitesi Yöntemi}

(DPPH)

DPPH radikal süpürücü aktivite yöntemi Blois'in metoduna göre yapıldı (Blois, 1958). Metanolik bitki ekstresinin $(100,250,500,750,1000 \mu \mathrm{g} / \mathrm{mL})$ ve bütillenmiş hidroksi toluen (BHT) standardın $(0.01,0.005,0.025,0.0125,0.00625 \mathrm{mg} / \mathrm{mL})$ farklı konsantrasyonları hazırland1. DPPH çözeltisi ise $100 \mu \mathrm{M}$ olacak şekilde metanolde çözülerek hazırlandı. $750 \mu \mathrm{L}$ DPPH çözeltisi, 750 $\mu \mathrm{L}$ metanolik bitki ekstresi çözeltileri üzerine eklenerek vortekslendi ve oda sicaklığında 50 dakika inkübe edildi. $517 \mathrm{~nm}$ 'de absorbanslar spektrofotometrik olarak okundu. Elde edilen sonuçlar grafiğe geçirildi ve $\mathrm{IC}_{50}$ değerleri $(\mathrm{mg} / \mathrm{mL})$ hesaplandı. Bu çalışmada standart olarak kullanılan BHT için aynı işlemler uygulandı.

\subsubsection{Ferrik Indirgeyici Antioksidan Güç (FRAP) Yöntemi}

Ferrik indirgeyici gücün belirlenmesi için Benzie ve Strain'in geliştirdiği yöntem modifiye edilerek kullanıldı (Benzie ve Strain, 1999). FRAP reaktifi $2.5 \mathrm{~mL}, 300 \mathrm{mM}$ (pH:3.6) asetat tamponu ile 40 $\mathrm{mM} \mathrm{HCl}$ ile hazırlanan $0.25 \mathrm{~mL}, 10 \mathrm{mM} \mathrm{TPTZ}$ ve $0.25 \mathrm{~mL}, 20 \mathrm{mM}$ demir (III) klorür çözeltileri karıştırılarak hazırlandı. Tüplere test numunesinden $50 \mu \mathrm{L}(100 \mu \mathrm{g} / \mathrm{mL})$ ve $1.5 \mathrm{~mL}$ FRAP reaktifi eklenerek vortekslendi. 30 dakika inkübasyondan sonra 593 nm'de absorbans ölçümü gerçekleştirildi. FRAP değeri gram numune başına $\mu \mathrm{M}$ troloks eşdeğeri olarak verildi.

\subsubsection{Antimikrobiyal Aktivite Tayini}

Antimikrobiyal aktivite tayinleri agar kuyucuk difüzyon yöntemi kullanılarak yapıldı (Woods vd., 2003). Çalışmamızda kullanılan test 
mikroorganizmaları şunlardır: Escherichia coli, Yersinia pseudotuberculosis, Pseudomonas aeruginosa, Staphylococcus aureus, Enterococcus faecalis, Bacillus cereus, Mycobacterium smegmatis bakterileri, Candida albicans mantar1 ve Saccharomyces cerevisiae mayası.

\subsubsection{Agar kuyucuk difüzyon metodu}

Test edilecek bakterilerin bir gecelik kültürlerinden, sıvı besiyeri içinde yaklaşık olarak $10^{6} \mathrm{kob} / \mathrm{mL}$ şeklinde dilüsyonlar hazırlanarak kat1 besiyerlerine yaygin ekimleri yapıldı. Ardından, steril cam boru ile besiyerleri üzerinde $2 \mathrm{~cm}$ aralıklarda, $5 \mathrm{~mm}$ çapında kuyucuklar açıldı. Ekstrenin $1 \mathrm{~mL}$ 'de hazırlanmış stok çözeltilerden her bir kuyucuğa $50 \mu \mathrm{L}$ damlatıldı. İnkübasyon işlemi bakteriler için 24 saat, mayalar için 48 saat olacak şekilde $36{ }^{\circ} \mathrm{C}^{\prime}$ de petrilerde yapild 1 ve inhibisyon zonları bir cetvel yardımı ile ölçüldü. Standard kontrol ilaç olarak bakteriler için Ampisilin $(10 \mu \mathrm{g})$, mayalar için flukonazol $(5 \mu \mathrm{g})$, $M$. smegmatis için Streptomycin ve standart çözücü kontrolü olarak metanol kullanıldı.

\subsubsection{Tirozinaz Enzim Aktivitesi Yöntemi}

Metanolik bitki ekstresinin tirozinaz enzim inhibisyonu aktivitesi standart olarak kojik asit kullanılarak Masuda yöntemine göre belirlendi (Masuda vd., 2005). $100 \mu \mathrm{L}$ fosfat tamponu (pH 6.8) 96 kuyucuklu mikroplakaya aktarılarak üzerine $25,50,100,500 \mu \mathrm{L}$ bitki ekstreleri ve 40 $\mu \mathrm{L}$ tirozinaz çözeltisinden eklendi. Oluşan karışım $25^{\circ} \mathrm{C}$ 'de 15 dakika inkübe edildi ve $40 \mu \mathrm{L}$ L-dopa ile muamele edildi. Ayrıca, tirozinaz enzim çözeltisi olmadan hazırlanmış tepkime reaktiflerine bitki ektresinden ilave edilerek kör çözeltisi hazırlandı. Absorbansları 10 dakikalık inkübasyonun ardından 492 nm'de okundu. Körlerin absorbansları bitki ekstresinden çıkarılarak gerçek absorbanslar elde edildi ve $\mathrm{IC}_{50}$ değerleri hesaplandi.

\subsubsection{HPLC}

Gallik asit, protokatekuik asit, protokatekul aldehit, $p$-hidroksi benzoik asit, klorogenik asit, vanilik asit, kafeik asit, vanilin, şiringaldehit, $p$ kumarik asit, ferulik asit, sinapik asit ve benzoik asit standart olarak kullanılan fenolik bileşiklerdir. İlk olarak, her standartı içeren stok çözelti 100 $\mu \mathrm{g} / \mathrm{mL}$ konsantrasyonda hazirland 1 ve $0.45 \mu \mathrm{m}$ membran filtreden geçirildi. Stok çözelti, 5-100 $\mu \mathrm{g} / \mathrm{mL}$ konsantrasyon aralığında seyreltilerek kalibrasyon eğrisi oluşturuldu. Fenolik bileşiklerin HPLC analizi [A: $2 \%$ asetik asit: su; B: $0.5 \%$ asetik asit asetonitril: su (1:1)], bir HPLC sistemi (Shimadzu Corporation, LC 20AT, Kyoto, Japonya) üzerinde $1.2 \mathrm{~mL} /$ dakika sabit bir çözücü akış oranında bir ters faz kolon kullanılarak gerçekleştirildi. Enjeksiyon hacmi $20 \mu \mathrm{L}$ olarak belirlendi. Sinyaller; 232, 246, 260, 270, 280, 290, 308 ve 328 nm'de, oda sicaklığında DAD dedektörü kullanılarak kaydedildi. Aliyazicioglu vd. (2017) metoduna göre uygulanan çözücü gradientleri şu şekildedir: $\% 5$ çözücü B ve $\% 95$ çözücü A (gradient uygulanmayan çözücü) oranlarında başlanan graident 41. dakikaya kadar belirli oranlarda çözücü B $\left(\begin{array}{lll}\% & 65\end{array}\right)$ gradienti artırlarak devam edildi. $270 \mathrm{~nm}$ ve $340 \mathrm{~nm}$ 'de kromatogramlar incelenerek fenolik asitlerin tanınması ve miktarının belirlenmesi için UV spektrumları ve alıkonma zamanları standartlarla karşılaştırıldı.

\section{Bulgular ve Tartışma}

ROS, yaşayan normal hücresel metabolizmanın bir sonucu olarak yaşamını sürdüren organizmalar tarafından üretilmektedir (Halliwell ve Gutteridge, 1999). Miktarları düşük ya da orta düzeyde olduklarında fizyolojik olarak işlev görüp organizmaya zarar vermemektedirler; fakat düzeyleri arttığında DNA, protein, lipit gibi hücre bileşenleri üzerinde yan etki oluşturmaktadırlar (Valko vd., 2006; Marnett, 1999). Oksidan/antioksidan dengenin oksidanlar yönüne kayması ile 'oksidatif stres' oluşmaktadır. Oksidatif stres; kanser, nörolojik bozukluklar (Lyras vd., 1997; Sayre vd., 2001), ateroskleroz, hipertansiyon, iskemi/perfüzyon (Dhalla vd., 2000; Kasparova vd., 2005), diyabet, çeşitli akciğer hastalıkları (pulmoner rahatsızlıklar, kronik obstrüktif akciğer hastalığı) (Asami vd., 1997) gibi birçok hastalığa sebep olmaktadır. Çalışmamızda antioksidan aktivitenin belirlenmesinde yaygın olarak kullanılan in vitro yöntemlerden toplam fenolik madde miktarının belirlenmesine dayanan Folin yöntemi, ferrik indirgeyici antioksidan güç (FRAP) ve 2,2-difenil1-pikrilhidrazil (DPPH) radikali temizleme yöntemleri (Lu vd., 2011) kullanılmıştır ve elde edilen sonuçlar Tablo 1'de gösterilmiştir. Yapılan literatür taramalarına göre, C. vulgare L. subsp. vulgare'nin antioksidan aktivitesi ile ilgili Tepe vd. (2007) tarafından yapılan bir çalışmada, $C$. vulgare uçucu yağının antioksidan aktivitesi, DPPH serbest radikal süpürme aktivitesi ile değerlendirilmiştir. Bu rapora göre, uçucu yă̆ fraksiyonunun serbest radikal temizleme potansiyeli $63.0 \mu \mathrm{g} / \mathrm{mL} \quad\left(\mathrm{IC}_{50}\right)$ olarak tespit edilmiştir. Villa-Ruano vd. (2013) Clinopodium macrostemum var. laevigatum ile yaptığı bir 
çalışmada DPPH yöntemine göre $\mathrm{IC}_{50}$ değerini $0.92-1.46 \mathrm{~g} / \mathrm{L}$ olarak rapor etmişlerdir. Başka bir çalışmada $C$. vulgare aseton, metanol ve su ekstrelerinin total fenolik içeriği sonuçlarına baktığımızda en yüksek değerin metanol ekstresinde (44.4 $\pm 1.75 \mathrm{mg}$ GAE/g ekstre) olduğu, DPPH sonuçlarına baktığımızda ise en yüksek değerin su ektresinde $(82.56 \pm 1.64 \mathrm{mg}$ TE/g ekstre) olduğu bulunmuştur (Sarikurkcu vd., 2015). Çalışmamızda elde edilen antioksidan aktivite değerlerinin literatür verileriyle uyumlu olduğu görülmektedir. Kullanılan bitkinin yetiştiği toprak içeriğinin, bitkinin toplandığ 1 bölgenin iklimsel özelliklerinin, kullanılan çözücü türünün farklı olmasindan dolayı farklılıkların görülebileceği düşünülmektedir. Mevcut çalışmada C. vulgare $\mathrm{L}$. subsp. vulgare'nin metanol ekstresinde gallik asit, protokatekuik asit, protokatekul aldehit, $p$-hidroksi benzoik asit, klorogenik asit, vanilik asit, kafeik asit, vanilin, şiringaldehit, $p$-kumarik asit, ferulik asit, sinapik asit ve benzoik asiti içeren 13 fenolik bileşenin varlığı (Şekil 1) ve miktarları araştırılmış, elde edilen bulgular Tablo 2'de verilmiştir. Bu verilere göre araştırılan ekstre bileşiminde bu bileşenlerden protokatekuik asit, klorojenik asit, vanilin, sinapik asit ve benzoik asit bulunmuştur (Şekil 2).

Tablo 1. Clinopodium vulgare L. subsp. vulgare ekstresinin antioksidan aktivitesi

\begin{tabular}{llll}
\hline Test bileşikleri & TPC $^{1}$ & FRAP $^{2}$ & DPPH $^{3}$ \\
\hline Ekstre & $27.9 \pm 0.4$ & $1556 \pm 3$ & $0.114 \pm 0.0004$ \\
BHT & & & $0.009 \pm 0.0001$
\end{tabular}

${ }^{1}$ Total fenolik içeriği (TPC) değeri ( mg gallik asid eşdeğeri/gram), ${ }^{2}$ FRAP değeri ( $\mu \mathrm{M}$ troloks eşdeğeri/gram), ${ }^{3} \mathrm{DPPH}$ $\mathrm{IC}_{50}$ değeri $(\mathrm{mg} / \mathrm{mL})$.

Tablo 2. Clinopodium vulgare L. subsp. vulgare ektresinde bulunan fenolik bileşikler

\begin{tabular}{lllll}
\hline & Bileşik & Alıkonma zamanı & Alan & Konsantrasyon (mg/L) \\
\hline 1 & Gallik asit & - & - & - \\
2 & Protokatekuik asit & 10.457 & 23114 & 0.918 \\
3 & Protokatekul aldehit & - & - & - \\
4 & $p$-hidroksi benzoik asit & - & - & - \\
5 & Klorogenik asit & 17.089 & 15104 & 1.508 \\
6 & Vanilik asit & - & - & - \\
7 & Kafeik asit & - & - & - \\
8 & Vanilin & 23.944 & 61602 & 1.323 \\
9 & Shiringaldehit & - & - & - \\
10 & $p$-kumarik asit & - & - & - \\
11 & Ferulik asit & - & - & - \\
12 & Sinapik asit & 32.410 & 87663 & 6.726 \\
13 & Benzoik asit & 34.416 & 198778 & 32.079 \\
\hline
\end{tabular}

Sarikurkcu vd. (2015)'nın yaptığı çalışmada $C$. vulgare'nin metanol ekstresinde protokatekuik asit, (+)-kateşin, $p$-hidroksi benzoik asit, klorojenik asit, kafeik asit, (-)-epikateşin, ferulik asit, benzoik asit, rutin, rosmarinik asit, apigenin tespit edilmiştir.

Fenolik bileşikler antioksidan etkili olduklarından bitkisel ağırlıklı beslenme ile bu bileşiklerin alımı vücutta radikal oluşumunu azaltarak kanser, damar hastalıkları gibi hastalıkların riskini düşürmektedirler. (Halliwell, 2007). Bitkinin fenolik içeriğinin yüksek çıkması çeşitli hastalıkların tedavisinde bu bitkinin ilaç hammaddeleri kaynağı oluşumuna katkısı bakımından önem arz etmektedir.

Mikroorganizmaların gelişmesini durdurabilen veya onları öldürebilecek ajanlara antimikrobiyal maddeler ad1 verilmektedir. Son y1llarda, antibiyotik direncine sahip mikroorganizmaların giderek artış göstermesi ile bu mikropların neden olduğu enfeksiyonların tedavisini zorlaşmaktadır. 


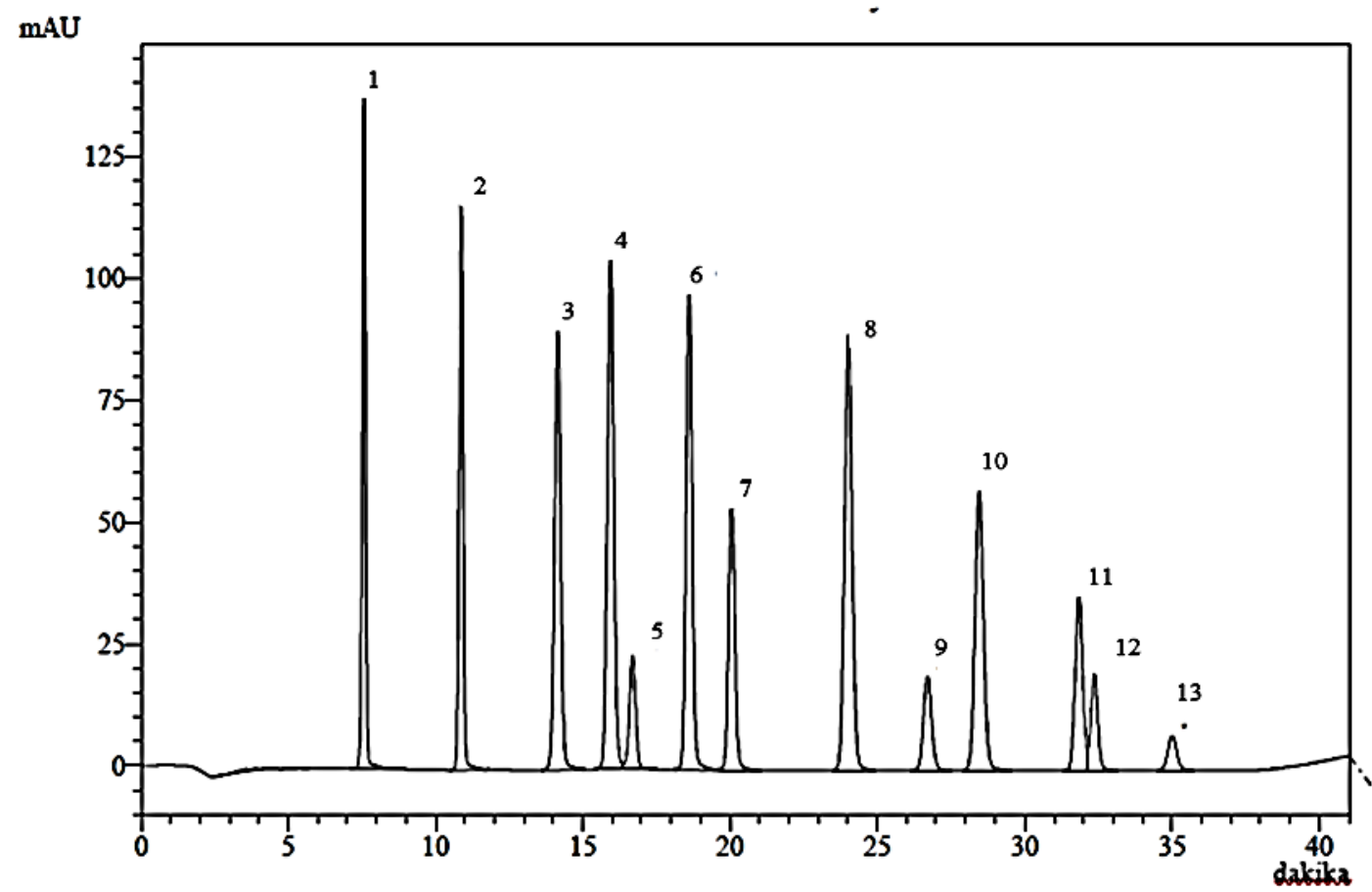

Şekil 1. Standart RP-HPLC kromatogramı. Pikler: (1) gallik asit, (2) protokatekuik asit, (3) protokatekul aldehid, (4) $p$-hidroksi benzoik asit, (5) klorogenik asit, (6) vanilik asit, (7) kafeik asit, (8) vanilin, (9) şiringaldehid, (10) ) $p$-kumarik asit, (11) ferulik asit, (12) sinapik asit, (13) benzoik asit.

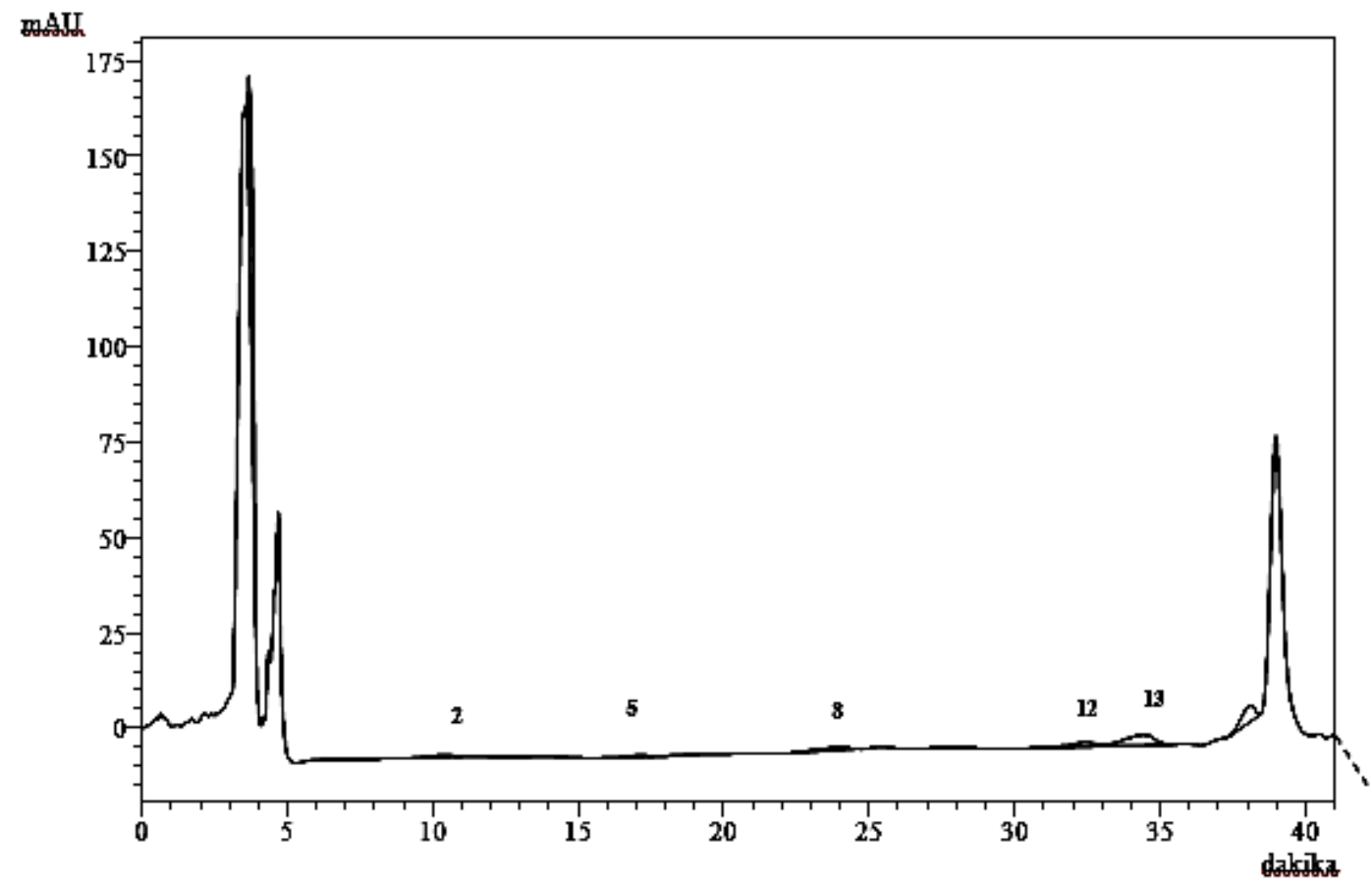

Şekil 2. Clinopodium vulgare L. subsp. vulgare HPLC kromatogramı. Pikler: (2) protokatekuik asit, (5) klorogenik asit, (8) vanilin, (12) sinapik asit, (13) benzoik asit.

Ayrıca antibiyotiklere direnç geliştiren bakterilerin varlığı, ilaç dirençliliğini artırmaktadır. Bu nedenler göz önüne alındığında, ilaçlara alternatif olarak tıbbi bitkilerin kullanılmasına ihtiyaç da artmaktadır (Yarnell ve Abascal, 2004). Bu amaçla, çalışmamızda $C$. vulgare L. subsp. vulgare'nin antimikrobiyal aktivitesi incelendi. Çalışılan mikroorganizmalar arasında bu bitkinin, en iyi etkisinin akciğer enfeksiyonu etkenleri olabilen grubu temsil eden $Y$. pseudotuberculosis (ATCC 911) üzerinde olduğu belirlendi (Tablo 3). Ayrıca, S. aureus, B. 
cereus ve M. smegmatis üzerinde de etki gözlendi. Clinopodium cinsinin başka bir türü olan $C$. bolivianum bitkisi ile Mohanty vd. (2017) E. coli üzerinde yapmış olduğu bir çalışmada bitkinin bakterinin yayılmasını engellediği fakat üremesini inhibe etmediğini bildirmişlerdir.

Saç rengini sağlayan faktörlerden biri olan melaninin görevi, deriyi UV ışınlarından korumak ve reaktif oksijen türlerini gidermektir. Tirozinaz enzimi, L-tirozinin monofenolaz ile hidroksilasyonunu ve L-dopanın difenolaz ile odopakinona oksidasyonunu katalizlemektedir (Chan vd., 2008). Tirozinaz, vücutta melanin sentezinin aşırı olmasından kaynaklanan cilt lekesi gibi hiperpigmentasyon ve sentezinin yeterli olmamasından kaynaklı hipopigmentasyon problemlerinde rol oynayan bir enzimdir. $\mathrm{Bu}$ enzimi inhibe eden ajanlar hiperpigmentasyon ve aktive eden ajanlar ise hipopigmentasyon problemlerinin tedavisinde kullanılabilir (Gholamhoseinian ve ZohreRazmi, 2012). C. vulgare'nin aseton ekstresinde tirozinaz inhibitör aktivitesinin $1.85 \pm 0.40 \mathrm{mg}$ galantamin eşdeğeri/g ekstre olarak bulunduğu belirtilirken metanol ektresinde hiçbir aktivitenin olmadığı belirtilmiştir (Sarikurkcu vd., 2015). Bizim çalışmamızda ise Sarikurkcu'nun çalışmasıyla uyumlu olarak $C$. vulgare $\mathrm{L}$. subsp. vulgare metanol ekstresinde $\mathrm{IC}_{50}$ değeri $(>1000 \mu \mathrm{g} / \mathrm{mL})$ standart olarak kullanılan kojik aside (63.095 $\mu \mathrm{g} / \mathrm{mL}$ ) göre oldukça yüksek bulunmuştur.

$\mathrm{Bu}$ çalışma sonucunda elde edilen verilere bakıldığında $C$. vulgare $\mathrm{L}$. subsp. vulgare metanol ekstresinin iyi bir antioksidan ve antimikrobiyal kaynağı olduğu ve faydalı fenolik bileşime sahip olduğu görülmüsstür. $\mathrm{Bu}$ nedenle çalış1lan tür doğal antioksidanların ve antimikrobiyallerin önemli bir kaynağı olarak düşünülebilir.

Tablo 3. Clinopodium vulgare L. subsp. vulgare ekstresinin antimikrobiyal aktivitesi (50 $\mu \mathrm{L})$

\begin{tabular}{llllllllll}
\hline & \multicolumn{1}{l}{ Mikroorganizmalar ve inhibisyon çap1 $(\mathrm{mm})$} & & \\
\cline { 2 - 11 } & Ec & $\mathrm{Yp}$ & $\mathrm{Pa}$ & $\mathrm{Sa}$ & $\mathrm{Ef}$ & $\mathrm{Bc}$ & $\mathrm{Ms}$ & $\mathrm{Ca}$ & $\mathrm{Sc}$ \\
\hline Ekstre & - & 12 & - & 6 & - & 8 & 6 & - & - \\
Ampisilin & 10 & 10 & 18 & 10 & 35 & 15 & - & - & - \\
Streptomisin & & & - & - & - & - & - & 25 & 25 \\
Flukonazol & - & - & - & - & - &
\end{tabular}

Ec: E. coli, Yp: Y. pseudotuberculosis, Pa: P. aeruginosa, Sa: S. aureus, Ef: E. faecalis, Bc: B. cereus, Ms: M. smegmatis, Ca: C. albicans, Sc: S. cerevisiae, (-): aktivite yok.

\section{Teşekkür}

S1la Özlem ŞENER ve Merve BADEM lisansüstü eğitimlerine destekleri için Türkiye Bilimsel ve Teknolojik Araştırma Kurumu (TÜBİTAK)'na teşekkür ederiz.

\section{Çıkar Çatışması}

Yazarlar arasında herhangi bir çıkar çatışması yoktur.

\section{Kaynaklar}

Aliyazicioglu, R., Demir, S., Badem, M., Sener, S.O., Korkmaz, N., Demi, E.A., Ozgen, U., Karaoglu, S.A., Aliyazicioglu, Y., 2017. Antioxidant, Antigenotoxic, Antimicrobial Activities and Phytochemical Analysis of Dianthus carmelitarum. Records of Natural Products, 11, 3, 270-284.
Asami, S., Manabe, H., Miyake, J., Tsurudome, Y., Hirano, T., Yamaguchi, R., Itoh, H. Ve Kasai, H., 1997. Cigarette smoking induces an increase in oxidative DNA damage, 8hydroxydeoxyguanosine, in a central site of the human lung. Carcinogenesis, 18, 9, 1763-1766.

Benzie, I.F.F. ve Strain, J.J., 1996. The Ferric Reducing Ability of Plasma (FRAP) as a Measure of "Antioxidant Power": The FRAP Assay. Analytical Biochemistry, 239, 70-76.

Birinci, S., 2008. Doğu Karadeniz Bölgesinde Doğal Olarak Bulunan Faydalı Bitkiler ve Kullanım Alanlarının Araştırılması. Yüksek Lisans Tezi, Çukurova Üniversitesi Fen Bilimleri Enstitüsü. Adana, 181s. 
Blois, M.S., 1958. Antioxidant determinations by the use of stable free radical. Nature, 181, 1199-1200.

Cao, G. ve Prior, R.I., 1999. The Measurement of Oxygen Radical Absorbance Capacity in Biological Samples. Methods in Enzymology, 299, 50-62.

Chan, E.W.C., Lim, Y.Y., Wong, L.F., Lianto, F.S., Wong, S.K., Lim, K.K., Joe, C.E. ve Lim, T.Y., 2008. Antioxidant and tyrosinase inhibition properties of leaves and rhizomes of ginger species. Food Chemistry, 109, 477-483.

Chen, J.S., Wei, C. ve Marshall, M.R., 1991. Inhibition mechanism of kojic acid on polyphenol oxidase. Journal of Agricultural and Food Chemistry, 39,1897-1901.

Çelikol, D., 2015. Hypericum perforatum bitkisinden elde edilen kantaron yağının yara iyileşmesi üzerine etkilerinin deneysel olarak incelenmesi. Doktora tezi, Cumhuriyet Üniversitesi, Ağız Diş ve Çene Cerrahisi Anabilim Dal, Sivas, 196s.

Dhalla, N.S., Temsah, R.M. ve Netticadan, T., 2000. Role of oxidative stress in cardiovascular diseases. Journal of Hypertension, 18, 655-673.

Dzhambazov, B., Daskalova, S., Monteva, A., Popov, N., 2002. In vitro screening for antitumour activity of Clinopodium vulgare L. (Lamiaceae) extracts. Biological and Pharmaceutical Bulletin Journal, 25, 499504.

Eruygur, N., 2014. Türkiye'de yetişen bazı Echium türlerinin yara iyileştirici aktivitesinin araştırılması. Doktora tezi, Gazi Üniversitesi Farmakognozi Ana Bilim Dal1, Ankara, 176s.

Gholamhoseinian A., ZohreRazmi Z., 2012. Screening the methanolic extracts of some plants for tyrosinase inhibitory activity. Toxicology Environment Chemistry, 94, 310-318.

Halliwell, B., 2007. Dietary polyphenols: Good, bad or indifferent for your health?. Cardiovascular Research, 73, 341-347.

Kasparova, S., Brezova, V., Valko, M., Horecky, J., Mlynarik, V., Liptaj, T., Vancová, O.,
Ulicná, O. ve Dobrota, D., 2005. Study of the oxidative stress in a rat model of chronic brain hypoperfusion. Neurochemistry International, 46, 601-611.

Kaur, C. and Kapoor, H.C., 2001. Antioxidants in fruits and vegetables-the millennium's health. International Journal of Food Science \& Technology, 36, 703-725.

Kokdil, G., 1998. Composition of the essential oil of Clinopodium vulgare ssp. arundanum (Boiss.) from two different localities in Turkey. Flavour and Fragrance Journal, 13, 170-172.

Lu, X., Wang, J., Al-Qadiri, H.M., Ross, C.F., Powers, J.R., Tang, J. ve Rasco, B.A., 2011. Determination of total phenolic content and antioxidant capacity of onion (Allium cepa) and shallot (Allium oschaninii) using infrared spectroscopy. Food Chemistry, 129, 2, 637644.

Lyras, L., Cairns, N.J., Jenner, A., Jenner, P. ve Halliwell, B., 1997. An assessment of oxidative damage to proteins, lipids, and DNA in brain from patients with Alzheimer's disease. Journal of Neurochemical Research, 68, 2061-2069.

Marnett, L.J., 1999. Lipid peroxidation DNA damage by malondialdehyde. Mutation Research, 424, 83-95.

Martos, I., Cosentini, M., Ferreres, F. ve TomasBarberan, F.A., 1997. Flavonoid Composition of Tunisian Honeys and Propolis. Journal of Agricultural and Food Chemistry, 45, 2824-2829.

Masuda, T., Yamashita, D., Takeda, Y. ve Yonemori, S., 2005. Screening for tyrosinase inhibitors among extracts for of seashore plants and identification of potent inhibitors from Garcinia subelliptica. Bioscience, Biotechnology, and Biochemistry, 69, 197-201.

Mohanty, S., Kamolvit, W., Zambrana, S., Sandström, C., Gonzales, E., Ostenson, C.G. ve Braunerf, A., 2017. Extract of Clinopodium bolivianum protects against $\mathrm{E}$. coli invasion of uroepithelial cells. Journal of Ethnopharmacology, 198, 214-220. 
Opalchenova, G. ve Obreshkova, D., 1999. Antibacterial action of extracts of Clinopodium vulgare L. curative plant. Drug Development and Industrial Pharmacy, 25, 323-328.

Perez, G.R.M., 2013. Antihepatotoxic, nephroprotective, and antioxidant activities of phenolic compounds from Satureja macrostema leaves against carbon tetrachloride-induced hepatic damage in mice. Medicinal Chemistry Research, 22, 1846-1855.

Sagdic, O., Kuscu, A., Ozcan, M. ve Ozcelik, S., 2002. Effects of Turkish spice extracts at various concentrations on the growth E. coli O157:H7. Food Microbiology, 19, 473-480.

Sarikurkcu, C., Ozer, M.S., Tepe, B., Dilek, E. ve Ceylan, O., 2015. Phenolic composition, antioxidant and enzyme inhibitory activities of acetone, methanol and water extracts of Clinopodium vulgare L. subsp. vulgare L.. Industrial Crops and Products, 76, 961-966.

Sayre, L.M., Smith, M.A. ve Perry, G., 2001. Chemistry and biochemistry of oxidative stress in neurodegenerative disease. Current Medicinal Chemistry, 8, 721-738.

Slinkard, K. ve Singleton, V.L., 1977. Total Phenol Analysis: Automation and Comparison with Manuel Methods. American Journal of Enology and Viticulture, 28, 49-55.

Soler-Rivas, C., Jolivet, S., Arpin, N., Olivier, J.M. ve Wihers, H.J., 1999. Biochemical and physiological aspects of Brown blotchdisease of Agaricus bisporus. FEMS Microbiology Reviews, 23, 591-614.

Soumitra, M., Witchuda, K., Silvia, Z., Corine, S., Eduardo, G., Claes-Goran, O. ve Annelie, Br., 2017. Extract of Clinopodium bolivianum protects against E. coli invasion of uroepithelial cells. Journal of Ethnopharmacology, 198,214-220.

Tepe, B., Sihoglu-Tepe, A., Daferera, D., Polissiou, M. ve Sokmen, A., 2007. Chemical composition and antioxidant activity of the essential oil of Clinopodium vulgare L.. Food Chemistry, 103, 766-770.

Tosun, A., Süntar, İ., Keleş, H., Kiremit, H., Asakawa, Y. ve Akkol, E., 2016. Wound Healing Potential of Selected Liverworts Growing in Turkey. Turkish Journal of Pharmaceutical Sciences, 13, 3, 285-291.

Turner, B.L., 2008. Taxonomic status of Clinopodium macrostemum (Lamiaceae), Phytologia, 90, 411-413.

Valko, M., Rhodes, C.J., Moncol, J., Izakovic, M. ve Mazur, M., 2006. Free radicals, metals and antioxidants in oxidative stress-induced cancer. Chemico-Biological Interactions, $160,1-40$.

Villa-Ruano, N., Pacheco-Hernandez, Y., ZuritaVasquez, G., Betancourt-Jiménez, M.B., Cruz-Duran, R., Duque-Bautista, H., 2013. Anti-lipase and antioxidant properties of 30 medicinal plants used in Oaxaca México. Biological Research, 46, 153-160.

Woods, G.L., Brown-Elliott, B.A., Desmond, E.P., Hall, G.S., Heifets, L., Pfyffer, G.E., Ridderhof, J.C., Wallace, R.J., Warren, N.C., Witebsky, F.G. 2003. In Susceptibility Testing of Mycobacteria, Nocardiae, and Other Aerobic Actinomycetes; Approved Standard, NCCLS document M24-A, 23, 18.

Yarnell, E. ve Abascal, K., 2004. The Leading Publisher in Biotechnology. Alternative Complementary Therapies, 5, 277-284. 